\title{
Non-Clostridial Gas Gangrene in the Diabetic Lower Limb
}

\author{
D. Bird ${ }^{1}$, A.E. B. Giddings ${ }^{2}$, and S. M. Jones ${ }^{2}$
}

Summary. Three cases of non-clostridial gas gangrene in diabetic lower limbs are reported. This rare condition occurs only in diabetes with peripheral neuropathy and is invariably fatal unless treated surgically. The clinical picture is deceptive with a slow, but insidiously progressive course, and the late appearance of skin necrosis. Antibacterial therapy is ineffective in preventing death. A serious delay may be fostered by inconclusive bacteriological investigations. Urgent radical amputation is required to save the patient's life.

Key words: Diabetes, gangrene, gas-forming infection.

Although the increased risk of infection in diabetic patients is widely known their particular susceptibility to non-clostridial gas-forming infection is sometimes overlooked. Delay in diagnosis often results while attempts are made to isolate clostridia. In non-clostridial gas gangrene diagnosis is essentially clinical and treatment must be by urgent surgery if a fatal outcome is to be avoided.

\section{Case histories}

1. Mrs. D. C., a 61-year-old housewife, was admitted at the request of the family doctor. Maturity onset diabetes mellitus had been diagnosed 21 years previously at the time of her hysterectomy and had been well controlled by diet and chlorpropamide $200 \mathrm{mg}$ daily. Three weeks prior to admission she had a verruca removed from the sole of her right foot. The wound began to heal

\footnotetext{
Surgical Registrar, present address: Royal Devon \& Exeter Hospital, Wonford, Exeter, Devon

2 Senior Surgical Registrar, Bristol Royal Infirmary, Bristol
}

satisfactorily, but two weeks later cellulitis was apparent and a necrotic ulcer developed on the dorso-medial aspect of the forefoot. This was treated with oral ampicillin, but the infection progressed rapidly and her diabetes became uncontrolled. The past history was unremarkable.

On admission to hospital she was pyrexial, but not clinically unwell. She did not complain of pain in the affected foot. There was diabetic retinopathy and sensory impairment below the midcalf level bilaterally, with sluggish knee jerks and absent ankle jerks. There was no superficial sign of ischaemia, but the right dorsalis pedis and posterior tibial pulses were impalpable. There was extensive cellulitis and oedema of the right foot and ankle although the plantar wound was clean. Crepitus was not detected clinically on admission but interstitial gas was demonstrated radiographically (Fig. 1).

Investigations showed a haemoglobin of $12.7 \mathrm{~g} / \mathrm{dl}$ and a white cell count of $22.9 \times 10^{9} 1^{-1}$. Serum electrolytes and urea were within normal limits. Blood glucose was $13.3 \mathrm{mmol} / 1$.

Bacteriological swabs from the ulcer grew Streptococcus faecalis, Escherichia coli and Bacteroides sp. The E. coli was resistant to ampicillin, and clindamycin and gentamicin were substituted. Gentamicin therapy was controlled on the basis of serial estimates of serum concentrations. Despite repeated attempts, no clostridia were isolated from the ulcer. During the next 7 days the diabetes was satisfactorily controlled by six hourly soluble insulin on a sliding scale and the patient remained pain free, although both pyrexia and leucocytosis persisted. The cellulitis progressed relentlessly and when necrosis appeared at the ankle, the opinion of a surgeon was sought.

Examination now showed extensive areas of necrosis and cellulitis extending to the knee (Fig. 2). A diagnosis of non-clostridial gas gangrene was made and a mid-thigh amputation performed that evening. Penicillin and gentamicin were given intramuscularly and continued for 4 days post-operatively. Dissection of the specimen showed that although the overlying skin appeared normal above the ankle, muscle necrosis had extended to the knee. There were multi-locular gas containing abscess cavities in the muscle and under the skin.

The patient made a good recovery and the wound healed by primary intention. The diabetes was controlled with oral agents at the time of discharge home.

2. A. W., a 60-year-old Polish woman, without previously diagnosed diabetes, was admitted with a gangrenous right foot with obvious crepitus up to the knee. There were no reflexes in the lower limbs and no pulses below the faintly palpable popliteals. X-ray showed chronic osteomyelitis of the right fifth metatar- 

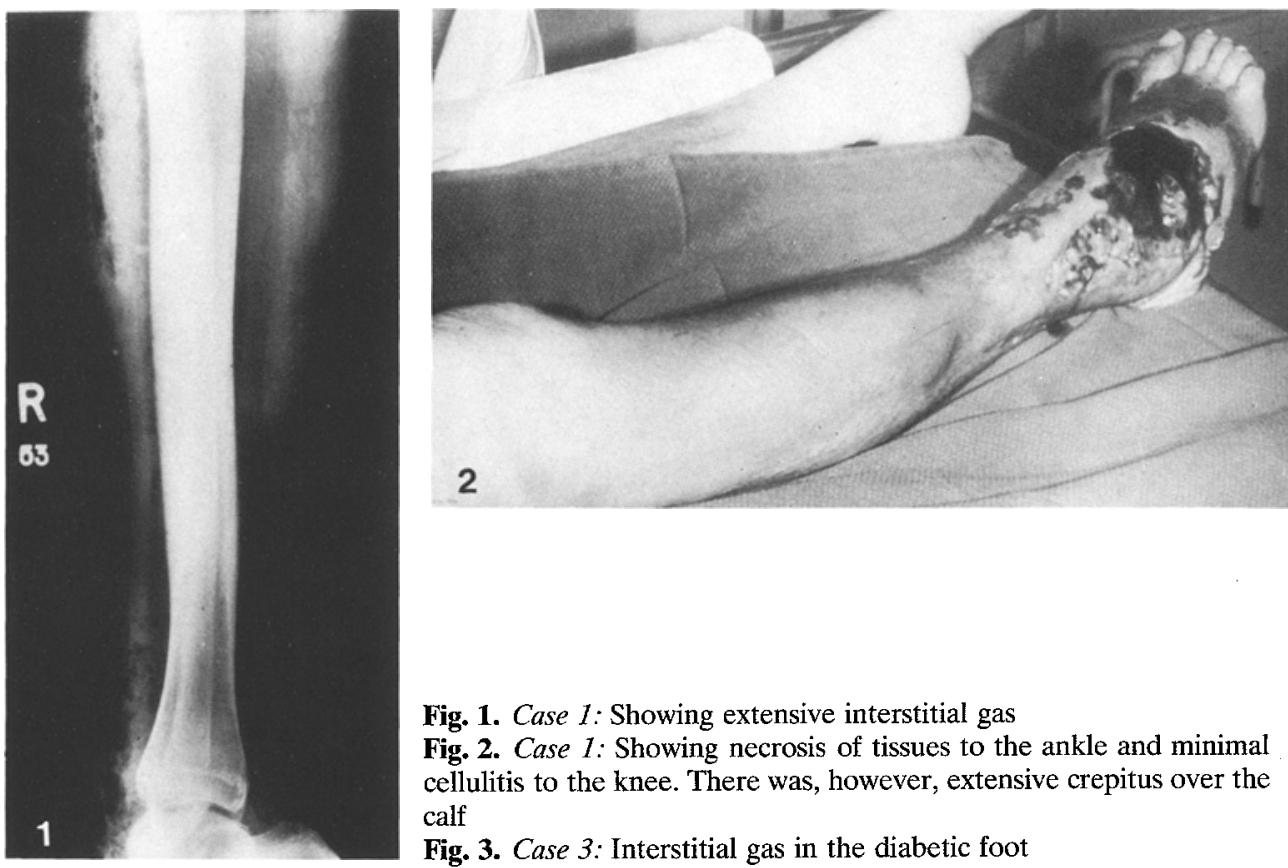

Fig. 1. Case 1: Showing extensive interstitial gas

Fig. 2. Case 1: Showing necrosis of tissues to the ankle and minimal cellulitis to the knee. There was, however, extensive crepitus over the calf

Fig. 3. Case 3: Interstitial gas in the diabetic foot

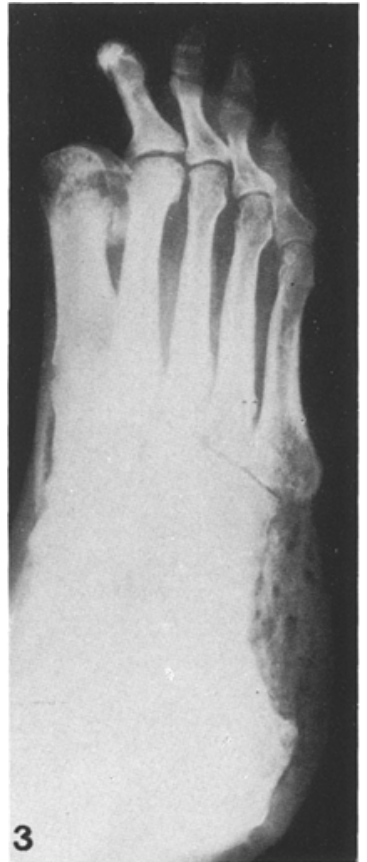

Table 1.

\begin{tabular}{|c|c|c|c|c|c|c|c|c|}
\hline Source & Cases & Survivors & $\begin{array}{l}E \\
\text { Coli }\end{array}$ & $\begin{array}{l}\text { Strept. } \\
\text { Faecalis }\end{array}$ & $\begin{array}{l}\text { Anaerobic } \\
\text { Strept. }\end{array}$ & Staph. & $\begin{array}{l}\text { Aerobic } \\
\text { Strept. }\end{array}$ & $\begin{array}{l}\text { Bacteroides } \\
\text { Sp. }\end{array}$ \\
\hline $\begin{array}{l}\text { Chiari (1893) } \\
\text { Hitschmann and }\end{array}$ & 1 & 0 & 1 & - & - & - & - & - \\
\hline Lindenthal (1899) & 2 & 0 & 2 & - & - & - & 1 & - \\
\hline Warren (1938) & 2 & & 2 & - & - & - & - & - \\
\hline Gillies (1941) & 1 & 1 & 1 & - & - & 1 & - & - \\
\hline $\begin{array}{l}\text { Spring et al. } \\
\text { (1951) } \\
\text { Wills \& Reece }\end{array}$ & 1 & 0 & 1 & - & - & - & - & - \\
\hline$(1960)$ & 4 & 0 & 3 & 1 & 1 & - & - & 1 \\
\hline Bird et al. & 3 & 2 & 2 & 2 & - & - & 1 & 1 \\
\hline
\end{tabular}

sal, with free gas extending into the calf and thigh. Blood glucose was $64.2 \mathrm{mmol} / \mathrm{l}$ and the plasma osmolality was $368 \mathrm{mosm} / \mathrm{l}$. She was treated with IV infusion of large volumes of hypotonic saline $(0.077 \mathrm{mmol} / \mathrm{l})$, insulin, potassium, ampicillin and chloramphenicol. That evening a right midthigh amputation was performed. She made a good recovery initially, but 24 hours later cardiac arrest occurred after a period of uncontrollable supraventricular tachycardia. Resuscitation was unsuccessful.

There was extensive liquefactive necrosis with gas formation in all muscle groups of the amputated limb. Cultures from the foot in life yielded a mixed growth of gut bacteria including Streptococcus faecalis and a beta-haemolytic streptococcus (Lancefield group B). Clostridia were not isolated. Blood cultures taken preoperatively proved sterile.

3. D. C., a 38-year-old man, was admitted as an emergency with a painful right foot and uncontrolled diabetes mellitus. He had been taking insulin for 27 years, and was currently receiving isophane 60 units and soluble 20 units in the morning and isophane 20 units and soluble 12 units in the evening. He had advanced nephropathy and retinopathy, and his severe peripheral neuropathy was responsible for repeated foot ulceration which had healed with bed rest in hospital. In 1963 his right great toe had been amputated for gangrene, as had the left second toe in 1964 and the left fifth toe in 1971.

In 1973 a right sternoclavicular abscess was successfully treated by serial aspirations and oral fusidic acid. Staphylococcus aureus was cultured from the aspirate.

In 1972 he suffered a stroke which had left him with a marked right hemiparesis.

On admission he was dehydrated, confused and pyrexial. The blood glucose was $23.0 \mathrm{mmol} / \mathrm{l}$.

There was an ischaemic ulcer on the right heel and the lateral aspect of the foot. The remaining right toes showed gangrenous patches. Sensation was grossly impaired and no pulses below the femorals were palpable in either leg. Free gas was demonstrated radiologically in the foot (Fig. 3). He was treated with soluble insulin, intravenous fluids and intramuscular ampicillin and cloxacillin.

As crepitus became clinically evident over the next three days he became increasingly feverish and confused. A swab taken from the ulcer grew Staphylococcus epidermidis, two different coliforms, and Alcaligenes odorans, results suggesting a superficially taken specimen. Intramuscular chloramphenicol was added to his treatment. He refused amputation and continued to deteriorate, 
with extension of the gas gangrene into the peroneal muscles. Careful attempts were made to isolate Clostridium welchii, but without success.

Eleven days after admission he consented to operation, and a right mid-thigh amputation was carried out successfully. He made a remarkable recovery, the wound healing by primary intention, and was walking well with a pylon four months later.

\section{Discussion}

Lesions of the feet in diabetics have been categorised by Oakley [1] as septic, ischaemic, neuropathic and combinations of all three, the last group being the largest and generally containing older patients. The clinical differentiation of these mechanisms is most important, since it determines the management and the prognosis of the lesion. Neuropathic lesions are usually painless unless infected, and heal without surgery in the majority of cases [2] a situation which had already occurred 12 years previously in our third case. Local amputation may accelerate healing and prevent recurrence. Failure of clear improvement with bed rest points to an ischaemic lesion, and conservative amputations far from helping may be followed by a dramatic extension of tissue necrosis. Even if this is avoided Catterall [3] reports only a $30 \%$ chance of wound healing and states that the majority will require an amputation above the ankle within one year. This difference between ischaemic and neuropathic lesions is well illustrated by the third of our patients, D. C., whose neuropathic lesions were successfully treated by a conservative policy over 12 years, but whose later ischaemic lesion led to non-clostridial gas gangrene and major amputation.

The syndrome of non-clostridial gas gangrene occurring in the lower limbs of diabetics was first described by Chiari in 1893 [4], and subsequently confirmed by Hitschmann and Lindenthal [5], and Warren [6]. Wills and Reece described four cases from the Bristol Royal Infirmary in 1960 [7], all in the lower limbs of longstanding diabetics with peripheral neuropathy but an apparently good circulation. All four patients died, three after delayed amputation. A review of the 67 diabetic patients who had developed gangrene of a lower limb at the Bristol Royal Infirmary in the subsequent fifteen years 1960 to 1975 has revealed no further cases until the three reported here.

Free tissue gas may be produced by physical insufflation occurring after penetration of the skin or perforation of an air-containing cavity, or induced by chemical means such as, hydrogen peroxide or magnesium salts [8]. The commonest organisms liberating gas into tissues are aerobic coliforms, al- though clostridia, bacteriodes and anaerobic or aerobic streptococci may all produce gas [9]. Anaerobic gas forming infections $[10,11]$ are generally clinically less dramatic than aerobic infections (with the exception of clostridial gas gangrene) but are insiduously progressive, more difficult to treat and potentially more lethal [12]. In serious anaerobic infections the bacteriological cultures may repeatedly show ordinarily non-virulent organisms. Such reassurance fosters delay and the early opportunity to save the patient's life may be lost. This is particularly true of anaerobic streptococcal gas gangrene but also occurs with synergistic gangrene $[13,14]$ due to microaerophillic streptococci and Staph. aureus. High mortality rates have been shown in acute der$\mathrm{mal}$ gangrene and necrotising fasciitis [15].

Non-clostridial gas forming infections may be due to aerobic or anaerobic bacteria [16]. They occur in many sites, commonly within the abdomen, but also in other sites including the perirenal space [17], perianally [18], the eye [19] and the urinary tract [20]. Diabetics appear to be more susceptible to such infections [21,22], which are usually due to the aerobe E. coli, although anaerobic streptococci acting alone may cause a similar condition in nondiabetics. Wills and Reece describe one case in a diabetic from which Bacteroides varius and Streptococcus faecalis were isolated and Gram positive cocci were also seen in sections of the material. The organisms isolated in these cases have been collected from reports in the literature and are shown in the Table. Since E. coli is the common cause, at present gentamicin or a cephalosporin are the most suitable best "guess" antibiotics, whilst ampicillin certainly is not. Chloramphenicol, preferably intravenously, would be an even better choice, being effective against most anaerobic bacteria and most strains of E. coli, and the slight risk of aplastic anaemia is acceptable in such a serious infection [23]. Its combination with the bacteriocidal penicillin derivatives probably does not give a significantly greater protection and may diminish the effectiveness of the penicillins. However, antibiotic therapy alone is unlikely to suffice; in the oedematous tissues penetration is poor and pre-existing diabetic microvascular disease may also hinder access [24].

The slow development of non-clostridial gas gangrene in the diabetic lower limb contrasts greatly with the acute onset, rapid progress and profound toxaemia of clostridial gas gangrene. The absence of pain in the affected limb may be due to the peripheral neuropathy which with associated microangiopathy and the raised tissue glucose concentrations favour extension of bacterial colonisation as originally shown by Chiari. 
The clinical presentation may be very misleading and seriously delay both diagnosis and treatment. The diagnosis is essentially clinical and an important sign is that of diminished or absent movement at the ankle joint. It should not be assumed that this is due to the extent of infection in the foot since the absence of pain characteristic of this condition makes it more likely to be the earliest sign of muscle necrosis. The extent of this necrosis is much greater than can be appreciated by inspection of the skin, large areas of which appear normal, as in our cases. Skin necrosis and crepitus may only appear at a late stage. Ischaemia may be present but need not be severe. In contrast clostridial myonecrosis produces more marked local pain and swelling, severe toxaemia and jaundice, with haemoglobinuria and haemoglobinaemia.

Where there is any doubt whether a lesion is clostridial gas gangrene, then it almost certainly is not, and the diagnosis of non-clostridial gas gangrene is likely to be correct. Both antibiotic policy and the value of hyper-baric oxygen are clearly defined in the treatment of clostridial infections, but these measures are ineffective in non-clostridial gas gangrene. Slack et al. [25] suggested that if there was no clinical improvement when a crepitant infection was so treated for three hours, then the infection was unlikely to be clostridial. Clostridial gas gangrene rarely occurs in diabetic gangrene [10]. In the 67 diabetics who developed gangrene of the lower limb at the Bristol Royal Infirmary between 1960 and 1975 there was only one case of clostridial gas gangrene and this arose after amputation. Penicillin prophylaxis and meticulous technique reduces the incidence of this post operative infection.

It may be concluded that a gas forming infection in the neuropathic leg of a diabetic is likely to be non-clostridial and is a particularly sinister condition. Antibiotic therapy, although theoretically correct as judged by in vitro sensitivity testing, will not control the infection, and there is a very high risk of septicaemia and death. A decision to amputate must be made urgently, and on clinical grounds alone.

Acknowledgements. We are grateful to Professor D.C. E. Speller for reviewing the bacteriological aspects of these cases, Professor J. H. Peacock, Dr.J.E. Cates and Dr. K.W. Heaton for permission to report cases under their care, and to the Department of Medical Illustration of the Royal Infirmary, Bristol for the preparation of illustrations.

\section{References}

1. Oakley, W., Catterall, R. C. F., Mencer Martin, M.: Aetiology and management of lesions of the feet in diabetes. Br. Med. J. 1956 II, 953-957
2. Malins, J.: In: Clinical diabetes mellitus, p. 243. London: Eyre and Spottiswoode 1968

3. Catterall, R.C.F.: The diabetic foot. Br.J.Hosp.Med. 7, 224-226 (1972)

4. Chiari, H.: Zur Bakteriologie des septischen Emphysems. Prague Med. Wochenschr. 18, 1-4 (1893)

5. Hitschmann, F., Lindenthal, O. Th.: Ein weiterer Beitrag zur Pathologie und Aetiologie der Gangrène foudroyante. Wien. Klin. Wochenschr. 13, 1057-1067 (1900)

6. Warren, S.: In: The pathology of diabetes mellitus, 2nd Edition, p. 160. Philadelphia: Lea and Febiger 1938

7. Wills, M. R., Reece, M.W.: Non clostridial gas infections in diabetes mellitus. Br. Med. J. 1960 II, 566-568

8. Meek, S. F., Prendergast, J. J., Harrold, G. C., McCord, C. P.: The physiologic action of metallic magnesium. J. Ind. Hyg. 24, 142-147 (1942)

9. Brightmore, T., Greenwood, T. W.: The significance of tissue gas and clostridial organisms in the differential diagnosis of gas gangrene. Br. J. Clin. Pract. 28, 43-50 (1974)

10. Atlemeier, W.A., Culbertson, W.R.: Acute non-clostridial crepitant cellulitis. Surg. Gynecol. Obstet. 87, 206 (1948)

11. Willis, A.T.: Anaerobic infections. Br.J.Hosp.Med. 12, 218-225 (1974)

12. Qvist, G.: Anaerobic cellulitis and gas gangrene. Br. Med.J. 1941 II, 217-221

13. Meleney, F.L.: Bacterial synergism in disease processes. Ann. Surg. 94, 961-981 (1931)

14. MacLennan, J.D.: Streptococcal infection of muscle. Lancet 1943 I, 582-584

15. Ledingham, I.McA., Tehrani, M.A.: Diagnosis, clinical course and treatment of acute dermal gangrene. Br. J.Surg. 62, 364-372 (1975)

16. Finegold, S.M., Rosenblatt, J.E.: Practical aspects of anaerobic sepsis. Medicine (Baltimore) 52, 311-322 (1973)

17. Gillies, C. I.: Interstitial emphysema in diabetes mellitus due to colon bacillus infection. J.A.M.A. 117, 2240-2242 (1941)

18. Brightmore, T.: Perianal gas producing infection of non-clostridial origin. Br. J. Surg. 59, 109-116 (1972)

19. Reis, W.: Gas bubbles in anterior chamber of eye, new differential diagnostic sign in metastatic coli-endophthalmia in diabetes. Pol. Gaz. Lek. 9, 570-571 (1930)

20. Foord, R.D., Nabarro, J.D.N., Riches, E.W.: Diabetic pneumaturia. Br. Med. J. 1956 I, 433-434

21. Spring, M., Kahn, S.: Non-clostridial gas infection in the diabetic. Arch. Intern. Med. 88, 373-377 (1951)

22. Mzabi, R., Himal, H. S., MacLean, L. D.: Gas gangrene of the extremity; the presenting clinical picture in perforating carcinoma of the caecum. Br. J. Surg. 62, 373-374 (1975)

23. Editorial: Chloramphenicol toxicity. Lancet 1969 II, 476

24. Atlemeier, W. A.: In: B.N. Carter (Ed.): Monographs on surgery, p. 59. New York: Thos. Nelson and Sons 1949

25. Slack, W. K., Hanson, G. C., Chew, H. E. R.: Hyperbaric oxygen in the treatment of gas gangrene and clostridial infection. Br. J. Surg. 56, 505-510 (1969)

Received: February 4, 1977, and in revised form: April 23, 1977

A. E. B. Giddings

Senior Surgical Registrar

The Royal Infirmary

Bristol BS2 8HW

Great Britain 